\title{
Developing strategic learning alliances: partnerships for the provision of global education and training solutions
}

\author{
Michael Crock, Gordon Joughin,* Pamela Edwards* and David Curtis** \\ *Griffith University, **University of South Australia \\ email: m.crock@mailbox.gu.edu.au
}

The paper describes a comprehensive model for the development of strategic alliances between education and corporate sectors, which is required to ensure effective provision of education and training programmes for a global market. Global economic forces, combined with recent advances in information and communication technologies, have provided unprecedented opportunities for education providers to broaden the provision of their programmes both on an international scale and across new sectors. Lifelong learning strategies are becoming increasingly recognized as an essential characteristic of a successful organization and therefore large organizations have shown a preparedness to invest in staff training and development. The demands for lifelong learning span a wide range of training and educational levels from school-level and vocational courses to graduate-level training for senior executives.

\section{Introduction}

The nature of higher education institutions is changing, primarily as a result of reduced government financial support for the sector. Fiscal restraint towards education funding has been observed in Australia, New Zealand, the United States, Canada, the UK and much of Europe. There has been steady growth in demand for higher education but reduced capacity by governments to fund it. Increasingly, students are required to contribute to the cost of their own education. Although these trends are problematic for higher education institutions that have been reliant previously upon government funding, it has also created an opportunity for those that are able to fill the gap between supply and demand for higher education services.

As well as changes affected by government, there have been changes to the nature of the demand for higher education. Universities and other education and training providers are 
facing the challenge of meeting the needs of a more diverse range of learners. Expectations in relation to time, place, nature and scope of the desired learning experience require institutions to provide a wider range of learner-centred experiences which are supported by quality assurance. The combined effect of increased and varied demand for higher education through massification policies and the reduction in public funding for education has meant that many education providers are looking to commercialize their educational programmes and services in an effort to maintain their sustainability. To do so requires a fundamental shift in the culture and structure of many traditional higher education providers.

Frew (1999: 21) suggests that educational institutions, including higher education, are being forced to be more competitive on the open market, to develop best practice and quality assurance, and to be customer-focused. He argues that the dominant traditional hierarchical culture of most universities does not support these practices. Instead, a culture that encourages creativity, innovation and institutional visibility, combined with a major focus on the bottom line, is advocated. The approach requires educational institutions to be able to adapt readily in response to an environment which is changing almost constantly.

Latham (1999) argues that networks are a natural mode of organization for an information society; they establish 'horizontal' relationships of trust, negotiation and reciprocity. By definition, a network has no centre of authority. Rather it relies on a dense web of collaboration, creativity and multi-skilling to secure its competitive success. The demands of multi-disciplinary and integrated research cannot be met without a close relationship between universities and other centres of knowledge. Similarly, stronger private resourcing of universities relies on the right kind of relationship with the private sector, going beyond strictly commercial relationships dominated by contractual obligations. Universities should be willing to commercialize their ideas directly and take a partnership role in industry clusters. This unique blend of collaboration and competition is a defining feature of the new network economies.

Latham (1999) concludes that there is a third way in higher education, beyond markets and hierarchies. It is the network university. While market-based systems may improve the quality of some universities, it is a poor way of dealing with equity. In the absence of growth funding, the current system of public hierarchies is delivering a lose-lose outcome deteriorating quality and equality across the university sector. $\mathrm{He}$ argues that only an adaptable system of network universities can deliver win-win results on every policy front.

The solution outlined in this paper is based on combining Latham's concept of a 'network university' and the concept of 'productive diversity' as described by Cope and Kalantzis (1997), which describes the development of strategic coalitions between traditional educational institutions and non-traditional organizations to allow for the provision of skills and new competencies required by individuals in government, academia and commerce. It is a pertinent concept, in light of postmodern views that emphasize pluralism, the breakdown of old boundaries and the need for new discourse which is inclusive of the 'other' (Goodenow, 1996: 197). This solution is reflected in our proposal to build partnerships with mutually suitable industries to develop effective learning alliances. Griffith Flexible Learning Services at Griffith University in Australia is already negotiating 
partnerships or 'learning alliances' with a variety of non-traditional industries in an effort to expand its flexible education programmes to meet the demands of global education markets.

\section{A framework to assist in identifying strategic partnerships}

To assist an education or training provider in identifying suitable strategic partnerships which will allow them to exploit global education markets, seven distinct operational business components have been identified (see Figure 1). These allow for a comprehensive approach in the provision of educational solutions and foreshadow the production, distribution and maintenance of digital content and for the management of commercial activities associated with that content. While these components cover a broad range of functions, they rely on close integration, flexibility and efficiency in delivery to ensure quality is not compromised.

\begin{tabular}{|c|c|c|c|c|c|c|}
\hline $\begin{array}{c}\text { Marketing, Sales } \\
\text { and Profile } \\
\text { (Global Profile) }\end{array}$ & $\begin{array}{c}\text { Service Interface } \\
\text { (Administration } \\
\text { Enrolment, } \\
\text { Management and } \\
\text { Certification) }\end{array}$ & $\begin{array}{c}\text { Delivery, } \\
\text { Interaction and } \\
\text { Online } \\
\text { Assessment } \\
\text { Tools }\end{array}$ & $\begin{array}{c}\text { Productivity } \\
\text { Tools for } \\
\text { Content } \\
\text { Generation and } \\
\text { Maintenance }\end{array}$ & $\begin{array}{c}\text { Delivery } \\
\text { Network } \\
\text { Infrastructure }\end{array}$ & $\begin{array}{c}\text { Storage and } \\
\text { Retrieval of } \\
\text { Digital IP } \\
\text { (Version and } \\
\text { Stock Control) }\end{array}$ & $\begin{array}{c}\text { e-Business } \\
\text { Solutions for } \\
\text { Digital } \\
\text { Products and } \\
\text { Services }\end{array}$ \\
\hline
\end{tabular}

Figure 1: Operational business components.

These seven components are described more fully below:

\section{Marketing, sales and profile (global profile)}

This component is required to identify and maintain profiles of existing and potential clients and associates. Profiles are then used to target market segments and support public relations functions for market positioning. This component also provides ongoing evaluation and assessment of other business components.

\section{Service interface (administration, enrolment, management and certification)}

This component interfaces with the e-Business solutions, the marketing component and the storage of digital IP (intellectual property) components. It allows clients to enrol via online and offline processing. It should feature extensive statistics and reporting details on a client's enrolment and progression through course materials, and provide a framework for client support services.

\section{Delivery, interaction and online assessment tools}

The elements of this component provide the means by which clients access course materials such as Web pages and other documents and provide efficient mechanisms to allow students to interact with academic staff and other students. The forms of interaction include email, group discussion forums, real-time communications such as chat and realtime audio and video links. Online assessment tools enable clients to undertake a variety of assessment items online to get feedback on their progress and to undertake assessment for credit towards their course. The tools also allow academic teams to create and manage online assessment. Additional features include the ability for students to submit electronic versions of assignments and to participate in course surveys via a Web-form interface. 


\section{Productivity tools for content generation and maintenance}

Productivity tools facilitate the cost-effective design, development and maintenance of the digital content by academic teams and production specialists. The productivity tools suite should provide a mechanism to upload content from a range of file formats and apply templates to format content according to pre-determined specifications. The tools should enable the auto generation of Dublin-Core/IMS compliant metadata based on the content provided. Since metadata facilitate the categorizing, storing, searching and retrieving of information, its auto-generation is essential in a large-scale enterprise. Automation tools are also required for activities such as the configuration of courses, group discussion areas, frequently asked questions, and site maps.

\section{Delivery network infrastructure}

This combines software, hardware and physical locations. The software provides Webbased serving of content; the hardware provides physical storage of content and connectivity to the Internet. A variety of physical locations needs to be identified to provide efficient access to content and services in key market locations. The delivery network infrastructure provides an internationally redundant array of systems - servers, routers, etc. - to allow any node to go offline without bringing the entire system down.

\section{Storage and retrieval of digital IP (version and stock control)}

As the amount of content that is created and stored on a Web server increases, the complexity of content management becomes exponentially critical to the success of the business. Each version of a document will be required to be managed through three key phases: creation, testing and online availability on the Internet. Maintenance of the content during a course and revision at the end of each course will also require a version control system to be implemented. This is to ensure that the most current information is available to the client. As each document is created, modified and deleted a time stamp will be applied indicating when and who modified a document. An index of modifications will be available to all users. It is essential that the system be able to interface to a Dublin Core/IMS compliant database to allow searching for modules and components, thereby providing a catalogue of IP components.

\section{E-business solutions for digital products and services}

The e-business solutions are required to manage the sales of, licensing of, and access to digital content and education and training support services. The solution is required to be able to sell access to modules, groups of modules (for example subjects), groups of groups of modules (for example degree programmes) and a range of support services. The solution is required to provide online real-time transactions to enable a client to undertake a module or modules and process their application and, for example, debit their credit card. The solution is required to provide offline processing of transactions to allow sales staff to enrol a group of clients from a corporation in a subject and then invoice the corporation. In addition the e-business solutions should manage the sales and/or licensing of a component to a third party.

Having established the necessity of the operational business components, the effectiveness of the components in various integrative models of commercial activity can be examined. These models highlight the potential for the development of strategic partnerships which afford holistic solutions to global education requirements in particular. The criteria for 
determining the suitability of each solution includes support for open standards, flexibility in modes of operation, stability of systems, operating systems software requirements, hardware requirements, scalability, security and portability.

\section{Commercial models and associated key drivers}

Four models for the commercialization of education and training intellectual property have been identified. These are the:

- multimedia production house model;

- open university provider model;

- open learning broker model;

- corporate university model.

Each commercial model varies in its market orientation, the locus of content ownership, technologies that are used, and in the business models they follow. A description of each model follows.

\section{The multimedia production house model}

The core of both conventional publication and multimedia publishing activities is the control over content. Two key elements for success include access to a total development solution comprising the multimedia production technology (development and deployment tools) and established marketing and distribution channels. In general, the multimedia publisher model has the core business components of marketing, sales and profile, productivity tools for content generation and maintenance, storage and retrieval of digital IP, and e-business solutions for digital products and services.

The multimedia production model assumes that providers own or source content which is to be produced in digital form - typically, a Web site or a CD-ROM. The production facility provides expertise in digital conversion of content for a particular audience. The multimedia industry has evolved over recent years with an expectation that it would grow along the lines of the publishing industry and indeed that large publishers would move into this area, seeing it as a segment of traditional publishing. At this stage there is little evidence of this occurring on a large scale in higher education and training markets. Some publishers distribute multimedia titles. Some multimedia titles have been based upon content that the publishers control, but it seems that they enter into partnerships with multimedia developers to produce titles. Companies that have been involved in software development have also moved into the production of multimedia titles, since good multimedia involves high levels of interactivity and this has required their software development skill sets.

\section{The open university provider model}

An open university model assumes that intellectual property is either sourced from within or bought and therefore owned by the institution. It also includes a production facility which is used to transform material and make it available to prospective clients. Courses are usually state-accredited, and access is open to anyone prepared to pay for access to resources and programmes. Delivery mechanisms range from face-to-face to sophisticated communications systems. In general, the open university provider model involves all seven 
core business components. As a business model, its key drivers include content, demand, management and administration.

\section{The open learning broker model}

Open learning brokers source content from established, reputable, usually state-accredited content providers, and make it available through marketing and distribution channels. They provide co-ordinating and client service functions, whilst the students are registered with the content provider. The key element of open learning brokerages is that they provide a marketing and management system and a key characteristic is that they source content from other providers. It is this characteristic that distinguishes them from open universities. Open learning brokers also provide a range of client support services. In general, the open learning broker model has the core business components of marketing, sales and profile, service interface, and delivery network infrastructure.

\section{The corporate university model}

Three sub-types of corporate universities have been identified:

- in-house training and development sections of large organizations;

- privately funded, for-profit accredited higher education providers; and

- publicly funded universities that are commercializing their activities through corporate structures.

All three sub-types of the corporate university model deliver programmes extensively via face-to-face means. However, in each there is evidence of increasing use of information and communications technologies to achieve access and efficiency objectives in programme delivery.

The first sub-type includes large corporations which have extensive involvement in ongoing staff development programmes from quite low-level vocational courses to advanced executive professional development programmes. Typically, they are not accredited, although some may seek accreditation directly or through partnership arrangements with higher education institutions. The in-house corporate training enterprise is very much demand-driven: the company identifies training needs as its products or business environment changes and it seeks to re-skill its staff so that their skill sets more closely match the emerging demands of its business. General Motors has articulated this in retasking a senior vice-president to convert its in-house training programmes and structures to form General Motors University. In doing this it argued that there was a need to ensure that its training programmes more closely reflected the corporation's strategic directions.

The second sub-type, large privately-funded profit-driven universities, offer programmes directed at employees in the corporate and public sectors. They are accredited and offer programmes from vocational through undergraduate to postgraduate levels. Large-scale private universities whose market is the corporate sector are also demand-driven but, rather than meeting the specific strategic objectives of a single entity, they seek to meet the needs of the sector at large or of several significant segments of that market.

These universities operate on a different model from mainstream higher education institutions. Traditional universities have four principal functions: teaching, research, consultancy and community service. Corporate universities focus on teaching, and 
constrain that focus to courses that are consistent with the needs of the parent organization. Their offerings may well be diverse, covering technical aspects of the business as well as executive development, financial matters and customer service. Research is in general a function of separate research and development divisions of the corporation. Some offer consultancy services about their products to partners. Community service is a part of general corporate citizenship rather than a specific focus of the university.

The third sub-type are publicly-funded universities that are increasingly seeking to commercialize their intellectual property by establishing wholly owned companies that operate in the corporate environment. These offer both established and newly developed courses to meet identified demand on a fee-for-service basis. Key drivers include available content and meeting demand. The demand may be from a single large corporate partner, or it could be directed at a particular industry or a segment of the general corporate market. In addition to the principal drivers of demand and content, other drivers are important in particular instances. In general, the corporate university provider model involves all seven-core business components.

\section{Summary of models}

The analysis of the models presented above suggests that a particular combination of business activity components is required to meet the challenges posed by emerging global markets successfully (see Figure 2). While there are strong contenders in the field, none yet have assembled all the key components required to satisfy the demands of the emerging opportunities optimally. Key drivers that are prevalent across all models relate to demand and content, with the technology and communications driver increasingly affecting capacity to deliver product to market.

\begin{tabular}{|c|c|c|c|c|c|c|c|}
\hline Component & $\begin{array}{l}\text { Marketing. } \\
\text { Sales and } \\
\text { Profile } \\
\text { (Global Profile) }\end{array}$ & $\begin{array}{c}\text { Service } \\
\text { Interface } \\
\text { (Administration } \\
\text { Enrolment, } \\
\text { Management } \\
\text { and } \\
\text { Certification) }\end{array}$ & $\begin{array}{c}\text { Delivery, } \\
\text { Interaction and } \\
\text { Online } \\
\text { Assessment } \\
\text { Tools }\end{array}$ & $\begin{array}{l}\text { Productivity } \\
\text { Tools for } \\
\text { Content } \\
\text { Generation } \\
\text { and } \\
\text { Maintenance }\end{array}$ & $\begin{array}{c}\text { Delivery } \\
\text { Network } \\
\text { Infrastructure }\end{array}$ & $\begin{array}{l}\text { Storage and } \\
\text { Retrieval of } \\
\text { Digital IP } \\
\text { Nersion and } \\
\text { Stock Control) }\end{array}$ & $\begin{array}{c}\text { e-Business } \\
\text { Solutions for } \\
\text { Digital } \\
\text { Products and } \\
\text { Services }\end{array}$ \\
\hline Multimedia Publisher & $\checkmark$ & $\checkmark$ & $\checkmark$ & $\checkmark$ & $\checkmark$ & & $\checkmark$ \\
\hline Open University Provid & ider & $\checkmark$ & $\checkmark$ & $\checkmark$ & $\checkmark$ & $\checkmark$ & \\
\hline Open Learning Broker & $\checkmark$ & & $\checkmark$ & & $\checkmark$ & & \\
\hline Corporate University & $\checkmark$ & $\checkmark$ & & $\checkmark$ & $\checkmark$ & $\checkmark$ & \\
\hline
\end{tabular}

Figure 2: Configuration of core business components across models.

\section{A model for Griffith University}

The four models considered represent familiar and well-established ways of operating. However, as Griffith University develops its approach to global education and training, it is apparent that no single model will encompass all the core business components that are required. Consequently, the university is investigating an integrated business model, incorporating a multimedia publishing arm and an arm associated with the online and 
distributed provision of education and training programmes, in both the corporate and higher education sectors, which includes many of the elements of the open university model.

The model suggested requires the university to focus its energies on the commercialization of both product development/publishing and programme delivery based on market demand, and its capacity to exploit existing and emerging information technologies. It requires a focus on the exploitation of the university's present strengths with respect to its emerging range of digital intellectual property and on harnessing the diverse range of commercialization activities spread across the academic elements and serviced through internal entities. It also demands concentration on the provision of quality client-focused products and services as a market differentiator.

When these requirements of the Griffith University model are considered in light of the core business components, the university emerges as a viable partner in a global enterprise that incorporates all of the components. Some of the components are already present in the university in an advanced form. Others are more highly developed in external organizations with whom partnerships have been, or are being, established. The following section outlines these components in the context of partnership strategies.

\section{Partnership strategies}

Marketing, sales and profile

Since its foundation in 1975 , Griffith University has developed a strong reputation as a provider of innovative educational solutions. It is seeking to build on its existing profile by developing productive, complementary relationships. The essence of marketing is relationships (not simply 'sales'), and involves relationships with existing and potential client organizations as well as with commercial partners.

\section{Service interface}

The university is entering into working relationships with organizations that provide stateof-the-art solutions to address human resource, finance and student administration requirements. A critical feature of these solutions is a client-driven service at all stages of service provision, from enquiries and enrolment to eventual certification.

\section{Delivery, interaction and online assessment tools}

Griffith University, through Griffith Flexible Learning Services, has developed a robust tools set for the development and delivery of flexible learning materials and for the administration and management of flexible learning programmes. The university will employ some of these tools and platforms. However, in deploying an integrated system of the scale envisaged and to maintain market leadership, it is necessary to ensure that all platforms are, and are maintained at, best practice standards. This will be achieved through a recently negotiated partnership with one of the leading developers of such platforms, giving the university access to state-of-the-art products while also enabling the university to inform the development of its partner's products in directions that meet its requirements. For our partner, access to the university's programmes as a real-world test and development environment will lead to more functional and robust products.

\section{Productivity tools for content generation and maintenance}

While Griffith Flexible Learning Services has developed a suite of tools for automating 
various aspects of Web site development, a significant enhancement of this capability will arise from a partnership with a local enterprise whose principal product enables the easy maintenance of sites by academics without the need for extensive training or technical support.

\section{Delivery network infrastructure}

In order to exploit national and international opportunities to distribute content, and therefore to benefit from economies of scale, multiple redundant servers are required, and for these to be operated efficiently, there is a requirement for high band width connections among them. The provision and management of this infrastructure is the province of major telecommunications operators and a partnership with one of these is desirable. End users may require connectivity, and a telecommunications operator with an ISP (Internet Service Provider) network would be an asset to the global education operation, would provide a needed service to clients and would in turn gain market share from the activity. The university continues to explore potential partnerships in this area.

\section{Storage and retrieval of digital IP}

The university is responding to the need for a digital repository to input, store, manage and retrieve intellectual property (including courseware, agreements and other information) in two ways. Firstly, the university is examining its own capabilities for identifying and managing a wide range of resources, including the adoption of appropriate metadata standards. Secondly, the university is exploring arrangements with potential partners on both an international basis and with respect to national partnerships or consortia.

\section{E-business solutions}

The university has developed an integrated set of solutions with respect to a number of business functions, including an e-commerce engine for financial transactions. E-business extends beyond the financial, and includes integrating a number of the core business components that have been discussed in this paper. The university has established a partnership with a major international consultant with a view to providing integrated education and training solutions on a whole-of-government/whole-of-organization basis.

\section{Conclusion}

The development of strategic partnerships between traditional as well as non-traditional higher education institutions are advocated for the continued sustainability of universities in a global economic environment. From a business perspective, holistic educational and training solutions are advocated, and several key elements have been identified which collaborative institutions would need to address in order to ensure their competitiveness in global education markets. Opportunities exist to develop global education and training businesses for those who can bring together a set of key elements of content, production, re-purposing content, effective delivery of content, and demand. However, the environment in which such businesses will operate is both competitive and changing rapidly.

Some providers have seen the opportunity and are moving into this area but to date no single provider has been able to assemble all required components. We would expect this situation to change as others perceive the shortcomings of an individual approach and form partnerships to complement their strengths. The models presented illustrate that 
existing approaches to education and training provision retain some gaps in services and products, thus strengthening the argument for identification of strategic alliances and partnerships with other partners. It is important for traditional education providers to analyse their particular strengths and weaknesses in order to identify suitable potential partnerships.

The obvious and immediate benefit of forming partnerships is the economic sustainability of higher education institutions. However, despite contrary arguments in some literature (Taylor, Rizvi, Lingard and Henry, 1997; Jarvis, 1996) the development of strategic partnerships also offers potential for the sustainability of social and cultural diversity on a global scale. The formation of new alliances with non-traditional partners will necessitate some organizational change within higher education institutions, allowing them to become more organic and adaptable, and thus better able to meet the diverse needs of learners from around the world.

\section{References}

Cope, B. and Kalantzis, M. (1997), 'Productive diversity: stories of organisations in the era of civic pluralism and total globalisation', Productive Diversity: A New Australian Model for Work and Management, Australia: Pluto Press.

Frew, B. (1999), 'Organisational culture: towards compatibility with the competitive environment', The Practising Administrator, 2, 18-21.

Goodenow. R. (1996), 'The cyberspace challenge: modernity, post-modernity and reflections on international networking policy', Comparative Education, 32 (2), 197-216.

Jarvis, P. (1996), 'Continuing education in a late-modern or global society: towards a theoretical framework comparative analysis', Comparative Education, 32 (2), 233-44.

Latham, M. (1999), 'The network university', Western Sydney Senior Staff Conference, Sydney, Australia.

Taylor, S., Rizvi, F., Lingard, B. and Henry, M. (1997), 'Globalisation, the state and education policy making', Education Policy and the Politics of Change, London: Routledge. 